\title{
Rancang Bangun Web Portal Berita Sebagai Sumber Informasi Berita Tentang Pertanian
}

\author{
Yudo Devianto*1, Saruni Dwiasnati ${ }^{2}$ \\ ${ }^{1,2}$ Fakultas Ilmu Komputer, Universitas Mercu Buana, Jakarta \\ e-mail: *11yudo.devianto@ mercubuana.ac.id, ${ }^{2}$ saruni.dwiasnati@ mercubuana.ac.id
}

\begin{abstract}
Abstrak
Pada era teknologi 4.0, perkembangan ilmu pengetahuan serta teknologi sangat pesat saat ini, terutama teknologi jaringan internet. Hampir semua belahan dunia memanfaatkan teknologi tersebut untuk mencari dan menyebarkan informasi.Begitu juga Indonesia, hampir sebagian besar warga negaranya memanfaatkan teknologi internet tersebut untuk mencari dan pemenyebarkan informasi. Berdasarkan hasil survey APJII 2018 pengguna internet masih memiliki persentase paling tinggi di pulau Jawa dan Sumatera. Melihat dari hasil survey tersebut, dengan memanfaatkan pengguna teknologi internet yang besar tersebut, akan dibuatkan suatu web portal berita dan web portal berita ini akan akan menginformasikan hanya berita tentang pertanian saja, yang dimaksud dengan pertanian disini adalah kegiatan pemanfaatan sumber daya hayati yang dilakukan manusia untuk menghasilkan bahan pangan, bahan baku industri, atau sumber energi. Portal berita ini akan dikhususkan untuk menginformasikan hasil pertanian dan produk-produk yang dihasilkan oleh pedesaan, agar dapat dikenal secara luas dan diharapkan dengan dikenal secara luas akan meningkatkan perekonomian masyarakat desa tersebut. Hal tersebut sejalan dengan undang-undang nomor 6 tahun 2014 "Tentang Desa", pasal 86 "Sistem Informasi Pembangunan Desa dan Pembangunan Kawasan Perdesaan ". Aplikasi portal berita E-News ini dirancang untuk dapat menginformasikan berita berkaitan dengan sektor pertanian. Aplikasi ini dibuat untuk membantu masyarakat mendapatkan informasi berita yang berkaitan dengan sektor pertanian. Dengan aplikasi portal berita E-News ini informasi berita yang berkaitan dengan sektor pertanian dapat tersampaikan ke masyarakat luas, khususnya masyarakat petani. Hasil dari penelitian ini adalah aplikasi portal berita E-News, yang dapat diterapkan untuk mengolah informasi berita yang berhubungan dengan sektor pertanian.
\end{abstract}

Kata kunci: portal berita, hasil pertanian, tentang desa

\begin{abstract}
In the era of technology 4.0, the development of science and technology is very rapid at this time, especially internet network technology. Almost all parts of the world use this technology to find and disseminate information. Likewise in Indonesia, most of its citizens use internet technology to find and disseminate information. Based on the results of the 2018 APJII survey, internet users still have the highest percentage on the islands of Java and Sumatra. We intend to create a news portal, but this news portal will inform only news about agriculture. What is meant by agriculture here is the use of biological resources by humans to produce food, industrial raw materials, or energy sources. This news portal will be devoted to informing agricultural products and products produced by villages, so that they can be widely known and it is hoped that being widely known will improve the economy of the village community. This is in line with law number 6 of 2014 "Concerning Villages", article 86 "Information Systems for Village Development and Rural Area Development". This E-News news portal application is designed to inform news related to the agricultural sector. With the news information from the
\end{abstract}


E-News news portal, the general public can find out about the development of the agricultural sector, and especially farmers get additional information related to the agricultural sector.

Keywords: news portal, agricultural produce, about the village

\section{PENDAHULUAN}

$\mathrm{P}$ ada era teknologi 4.0, perkembangan ilmu pengetahuan serta teknologi sangat pesat saat ini, terutama teknologi jaringan internet [2]. Hampir semua belahan dunia memanfaatkan teknologi tersebut untuk mencari dan menyebarkan informasi.

Begitu juga Indonesia, hampir sebagian besar warga negaranya memanfaatkan teknologi internet tersebut untuk mencari dan menyebarkan informasi [20]. Berdasarkan hasil survey APJII 2018 pengguna internet masih memiliki persentase paling tinggi di pulau Jawa dan Sumatera [3].

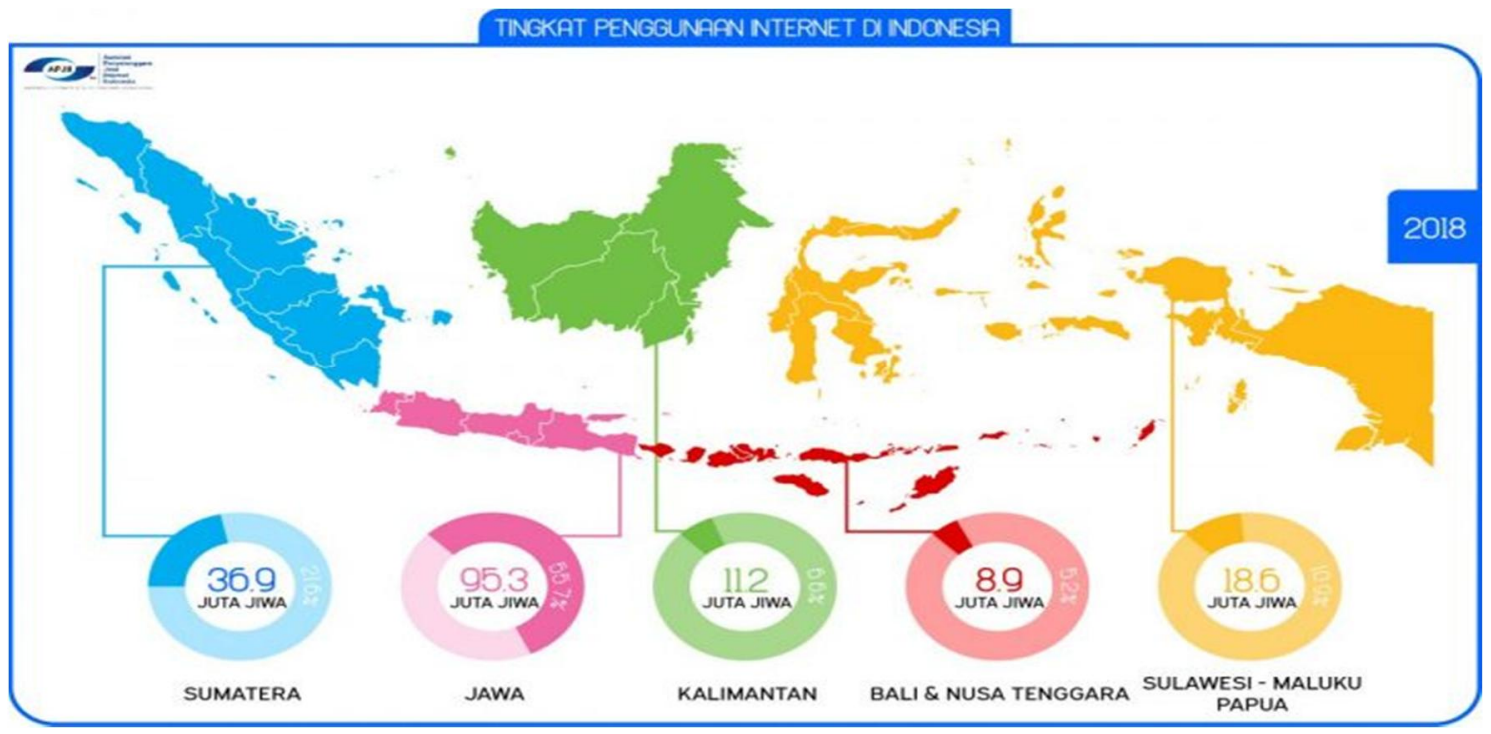

Gambar 1. Hasil Survey APJII 2018 Tingkat Pengguna Internet Indonesia

Melihat dari hasil survey tersebut, dengan memanfaatkan pengguna teknologi internet yang besar tersebut, akan dibuatkan suatu web portal berita [10,11, 12, 13, 14, 15, 17], dan web portal berita ini akan menginformasikan hanya berita tentang pertanian saja, yang dimaksud dengan pertanian disini adalah kegiatan pemanfaatan sumber daya hayati yang dilakukan manusia untuk menghasilkan bahan pangan, bahan baku industri, atau sumber energi, serta untuk mengelola lingkungan hidupnya. Kegiatan pemanfaatan sumber daya hayati yang termasuk dalam pertanian biasa dipahami orang sebagai budidaya tanaman atau bercocok tanam (bahasa Inggris: crop cultivation) serta pembesaran hewan ternak (raising), meskipun cakupannya dapat pula berupa pemanfaatan mikroorganisme dan bioenzim dalam pengolahan produk lanjutan, seperti pembuatan keju dan tempe, atau sekadar ekstraksi semata, seperti penangkapan ikan atau eksploitasi hutan [4].

Portal berita ini akan dikhususkan untuk menginformasikan hasil pertanian dan produkproduk yang dihasilkan oleh pedesaan, agar dapat dikenal secara luas dan diharapkan dengan dikenal secara luas akan meningkatkan perekonomian masyarakat desa tersebut. Hal tersebut 
sejalan dengan undang-undang nomor 6 tahun 2014 "Tentang Desa", pasal 86 "Sistem Informasi Pembangunan Desa dan Pembangunan Kawasan Perdesaan “ [1].

\section{METODE PENELITIAN}

Jenis penelitian yang kami gunakan adalah penelitian terapan (Applied Research), karena dari hasil penelitian dapat langsung digunakan/diterapkan untuk memecahkan permasalahan yang dihadapi dan pelaksanaan perancangan e-business [5] dengan menggunakan metode information systems development (ISD).

Metode tradisional systems development life cycle (SDLC) memberikan langkahlangkah terstruktur dan formal. Namun metode tersebut perlu diubah untuk menyesuaikan dengan kondisi teknologi informasi dan kebutuhan yang semakin kompleks dan memerlukan flexibility serta responsiveness yang besar. Berbagai metode modern tersedia untuk pengembangan sistem yang kompleks atau yang diinginkan cepat terwujud misalkan prototyping, joint application design, object oriented development, dan component-based development [6].

Untuk pengembangan e-business dalam klaster ini, gabungan antara keunggulan SDLC yang terstruktur dan formal, serta prototyping dan component based development akan diterapkan.

Dalam penelitian ini tidak akan membahas tentang pengolahan data berita melainkan akan dibuat antar muka portal berita yang akan digunakan untuk dapat membantu untuk menyebarluaskan informasi hasil pertanian dan produk-produk yang dihasilkan oleh pedesaan ke masyarakat luas di luar desa tersebut, hasil pertanian yang dimaksud seperti kemiri, asam, kenari dan produk olahan dari hasil pertanian.

Metode pengumpulan data yang digunakan dalam penelitian ini adalah [7, 8]: 1. Metode observasi. Observasi atau pengamatan langsung terhadap obyek penelitian. Teknik observasi dilakukan dengan observasi berstruktur dengan menyiapkan daftar kebutuhan data dan sumber data. 2. Metode studi pustaka. Metode pengumpulan data yang diperoleh dengan mempelajari, meneliti, dan membaca buku, informasi dari internet, jurnal, skripsi, tesis yang berhubungan dengan e-business dan desa.

\section{HASIL DAN PEMBAHASAN}

\subsection{Perancangan Sistem}

Perancangan sistem menentukan bagaimana sistem akan memenuhi tujuan tersebut, dalam hal ini: perangkat keras, perangkat lunak, infrastruktur jaringan, antarmuka pengguna, formulir dan laporan, serta program khusus, database, dan file yang diperlukan [9]. Perancangan sistem merupakan tahap lanjut dari analisis sistem, dimana perancangan sistem digambarkan sebagai sistem yang akan dibangun sebelum pengkodean dalam suatu bahasa pemrograman. Dalam mendesain sistem tidak lepas dari hasil analisisnya. Gambar di bawah ini menunjukkan desain sistem dalam penelitian ini. 


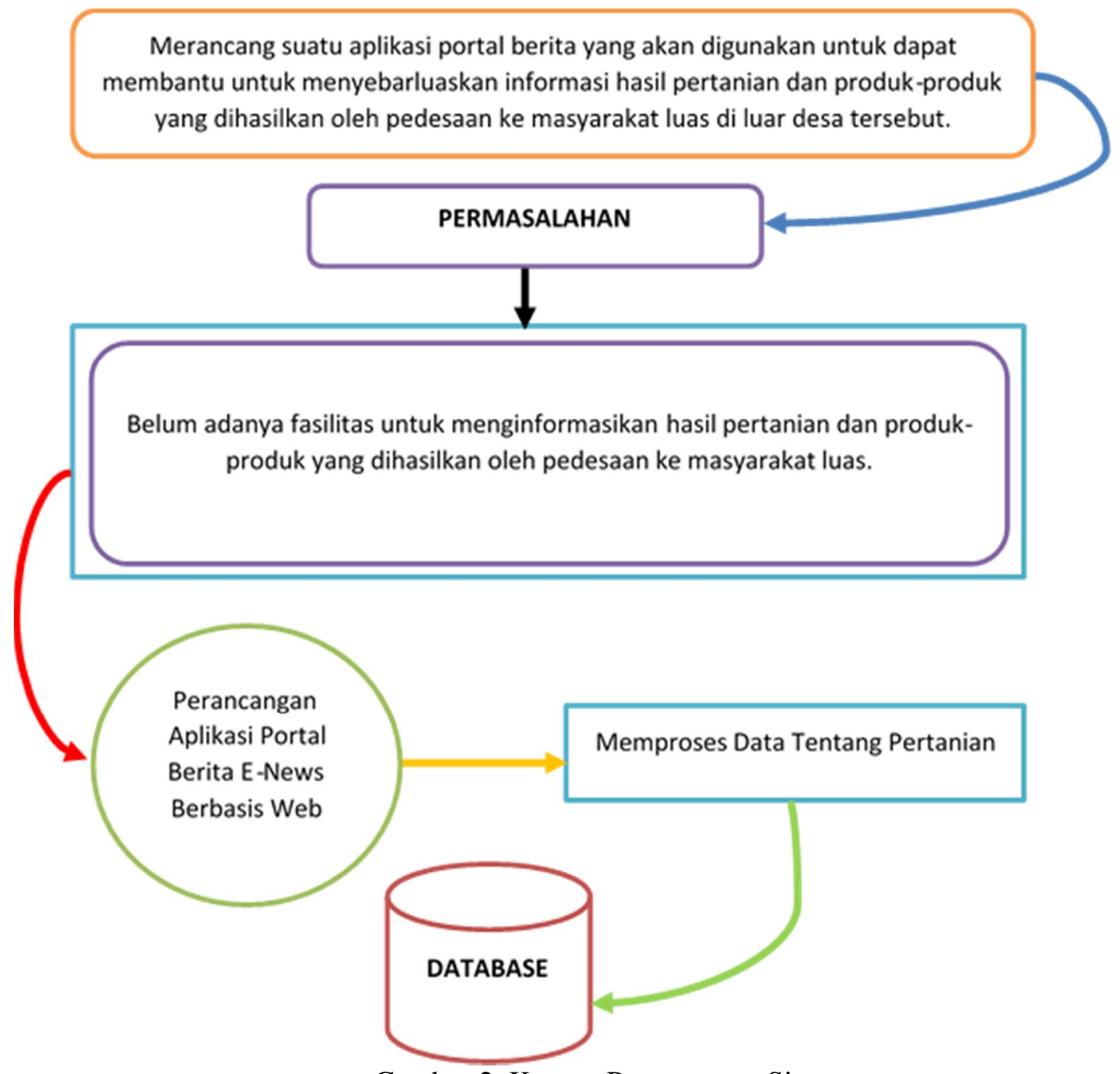

Gambar 2. Konsep Perancangan Sistem

Konsep perancangan sistem secara umum dapat dijelaskan sebagai berikut: Pada saat melakukan penelitian akan dilakukan pembuatan rancangan aplikasi portal berita E-News berbasis web, dan perancangan ini diharapkan dapat diimplementasikan untuk dapat menyelesaikan permasalahan yang ada yaitu tidak terdapat fasilitas untuk memberi tahu komunitas luas tentang produk pertanian yang dihasilkan serta produk yang tersedia, yang diproduksi di daerah pedesaan tersebut.

\subsection{Deployment Diagram}

Deployment Diagram adalah diagram arsitektur yang secara visual menampilkan dan menjelaskan hubungan antara perangkat keras dan perangkat lunak dari suatu aplikasi [18]. Arsitektur jaringan yang terbentuk merupakan kumpulan node yang berupa hardware dan software yang menggunakan prosesor dan perangkat lain untuk mengkonfigurasi runtime komponen software. Penyebaran merinci cara menyebarkan komponen dalam infrastruktur sistem, di mana komponen akan ditempatkan (di komputer, server atau PC), bagaimana fungsi jaringan di lokasi itu, spesifikasi server, dan masalah fisik lainnya. Node adalah server, workstation, atau perangkat keras lain yang digunakan untuk menyebarkan komponen di lingkungan sebenarnya. Hubungan antara node (seperti TCP / IP) dan persyaratan juga dapat

Devianto, et., al [Rancang Bangun Web Portal Berita Sebagai Sumber Informasi Berita Tentang Pertanian] 
ditentukan dalam diagram ini. Berikut diagram deployment dari desain aplikasi portal berita ENews yang akan dilakukan.

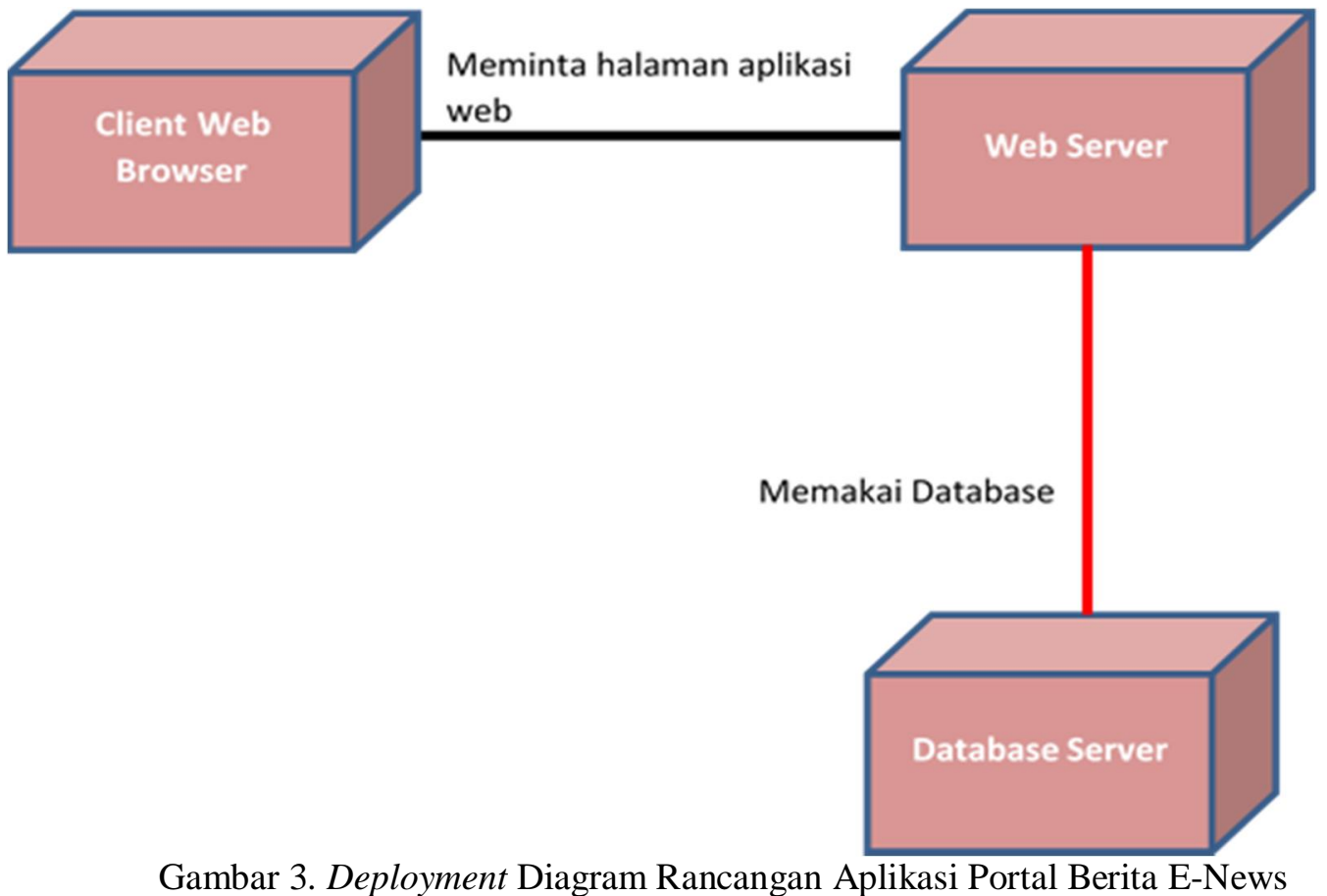

Dari gambar deployment diagram dapat dijelaskan sebagai berikut, 1. Client Web Browser lokasi dimana aplikasi portal berita E-News akan dijalankan, ketika aplikasi dijalankan, akan memunculkan halaman aplikasi portal berita E-News yang berada pada Web Server. 2. Web Server lokasi dimana aplikasi portal berita E-News berada, pada saat halaman aplikasi di munculkan di Client Web Browser, aplikasi tersebut juga menggunakan database yang berada pada Database Server. 3. Database Server lokasi dimana database yang dibutuhkan oleh aplikasi portal berita E-News berada.

\subsection{Perancangan Proses Bisnis}

Proses bisnis adalah proses yang menggambarkan proses kerja atau mekanisme kerja yang dilakukan oleh suatu unit atau pihak terkait, dan proses menggunakan atau menghasilkan dokumen atau data [19].

Dari gambar proses bisnis diatas dapat dijelaskan sebagai berikut, dapat dilihat pada proses bisnis, aplikasi portal berita E-News dikelola seorang editor berita, berita yang dikirimkan oleh para kontributor berita akan diperiksa atau diolah terlebih dahulu oleh editor berita, apakah berita tersebut layak untuk diterbitkan. Suatu berita yang dianggap layak akan ditampilkan pada portal berita E-News, dan masyarakat luas dapat melihat berita yang disajikan pada portal berita E-News tersebut. 


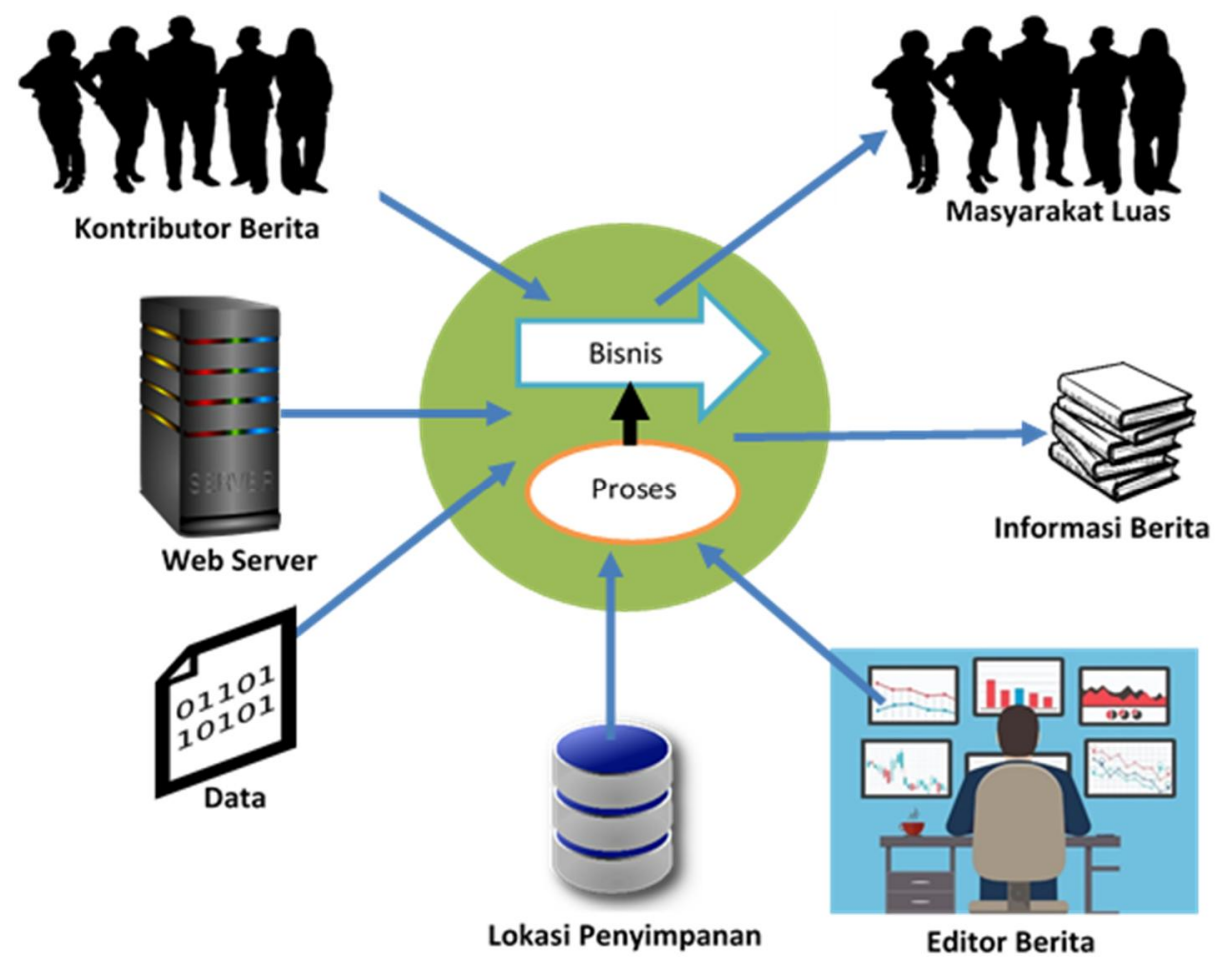

Gambar 4. Perancangan Proses Bisnis Aplikasi Portal Berita E-News

\subsection{Perancangan Infrastruktur Arsitektur}

Didalam perancangan infrastruktur arsitektur ini akan dijelaskan rancangan aplikasi portal berita E-News yang akan digunakan untuk mengolah data sekitar bidang pertanian, dan nantinya data tersebut menjadi informasi yang dapat dipercaya dan dapat dilihat oleh masyarakat luas.

Desain rancangan infrastruktur arsitektur Aplikasi Portal Berita E-News dapat dilihat pada gambar dibawah ini.

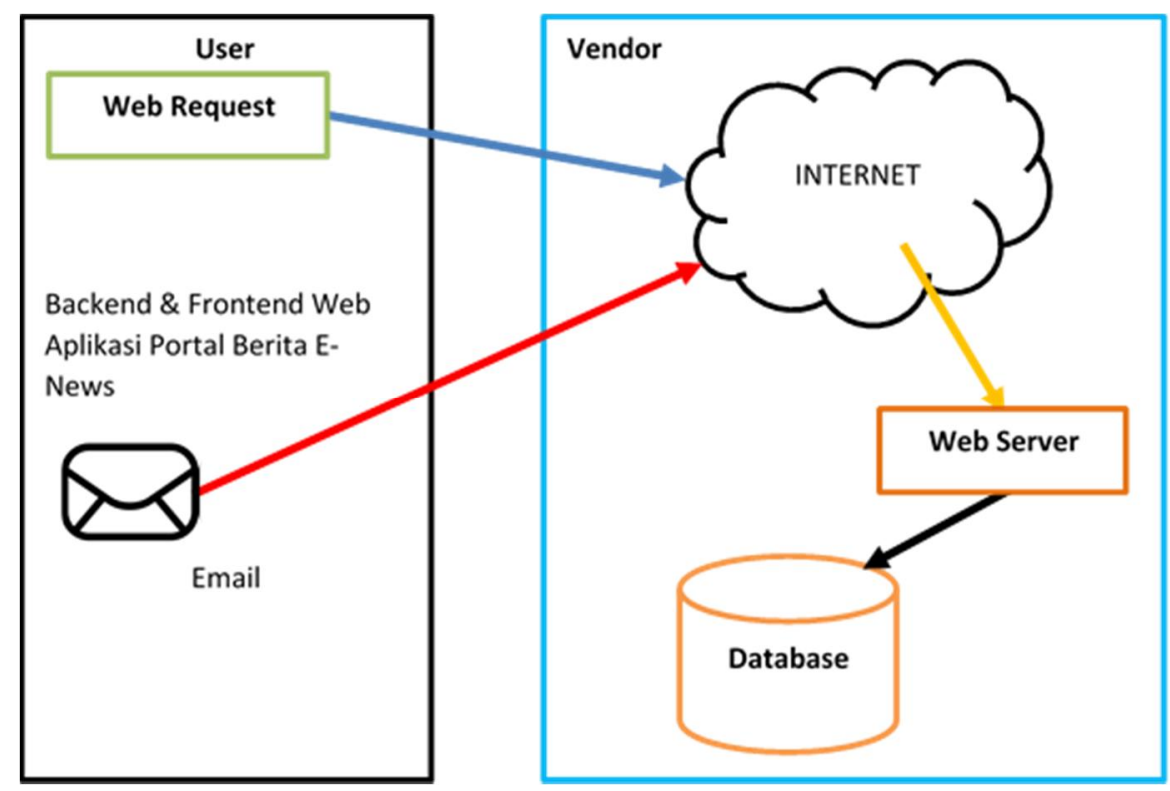

Gambar 5. Desain Infrastruktur Rancangan Aplikasi Portal Berita E-News 
Pada gambar desain infrastruktur Rancangan Aplikasi Portal Berita E-News dapat dijelaskan sebagai berikut: Pada bagian user terdapat frontend, backend dan email, para kontributor berita dalam menginformasikan berita dapat menggunakan fasilitas backend web aplikasi portal berita dan email, informasi-informasi berita tersebut diperiksa dan disortir oleh editor, bila layak ditampilkan, akan di ijinkan tayang dengan menggunakan fasilitas pada backend web aplikasi portal berita. Informasi berita yang sudah melalui jalur pengesahan oleh editor akan ditayangkan pada halaman frontend web aplikasi portal berita agar masyarakat luas dapat melihat berita yang ditayangkan pada halaman frontend web aplikasi portal berita[16].

Pada bagian vendor adalah lokasi dimana aplikasi portal berita E-News disimpan beserta database, melalui frontend dan backend web aplikasi portal berita dijalankan, untuk mengakses aplikasi portal berita E-News memanfaatkan jaringan internet.

\subsection{Konstruksi Antar Muka}

Pada tahap ini akan dibangun antarmuka untuk aplikasi portal berita E-News.

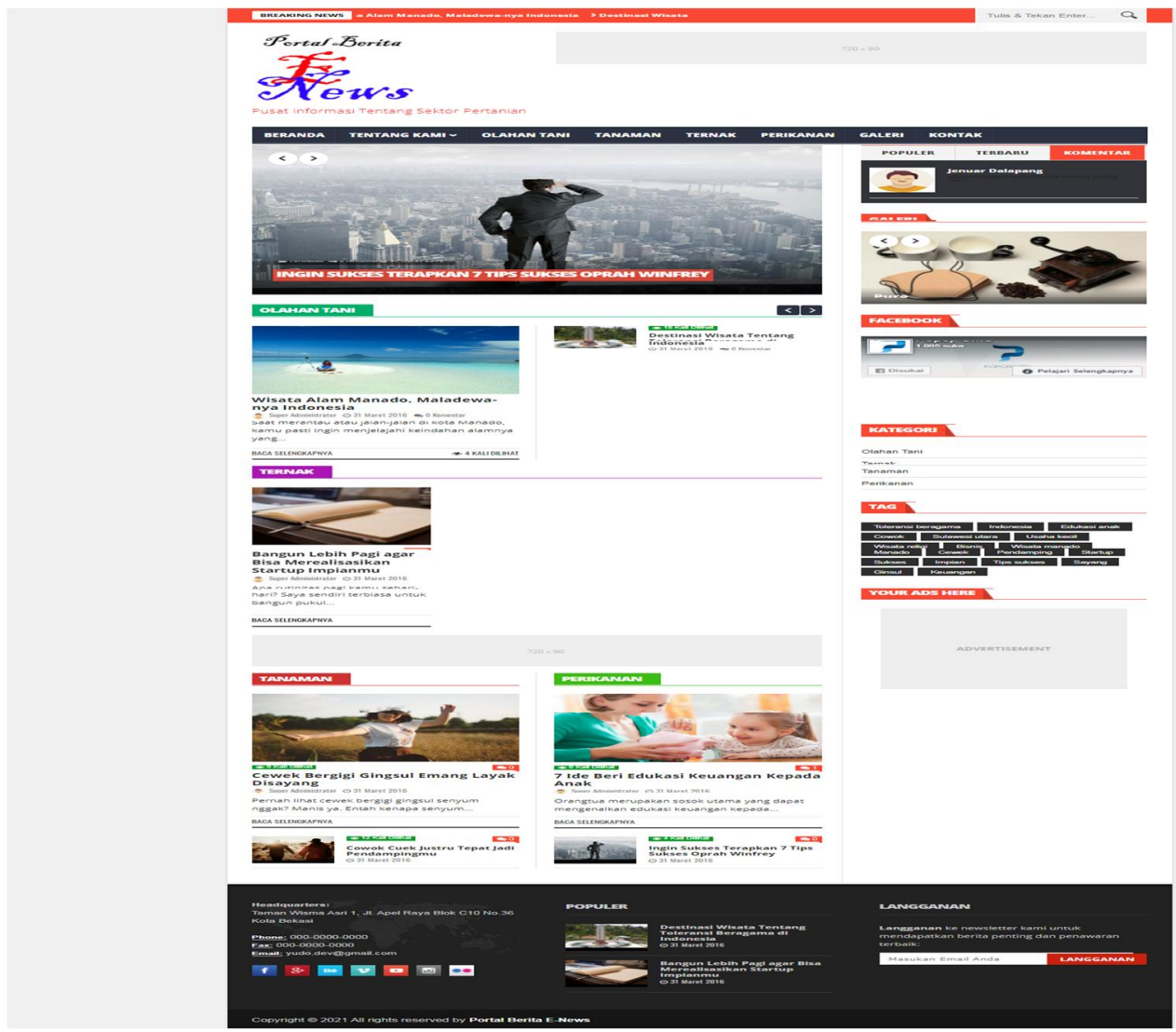

Gambar 6. Frontend Aplikasi Portal Berita E-News

Pada gambar antarmuka frontend aplikasi portal berita E-News terdapat beberapa menu, seperti terlihat pada tabel berikut ini. 
Tabel 1. Menu Frontend Aplikasi Portal Berita E-News

\begin{tabular}{ll}
\hline Menu & Keterangan \\
\hline Beranda & $\begin{array}{l}\text { Berisi slidebar dari kategori informasi seputar } \\
\text { pertanian, berisi juga berita terpopuler, terbaru dan } \\
\text { komentar. }\end{array}$ \\
\hline Tentang Kami & Berisi informasi tentang aplikasi portal berita E-News. \\
\hline Olahan Tani & $\begin{array}{l}\text { Berisi informasi berita tentang produk olahan dari } \\
\text { sector pertanian. }\end{array}$ \\
\hline Tanaman & Berisi informasi berita tentang budidaya tanaman. \\
\hline Ternak & Berisi informasi berita tentang budidaya ternak. \\
\hline Perikanan & Berisi informasi berita tentang budidaya ikan. \\
\hline Galeri & $\begin{array}{l}\text { Berisi gambar-gambar atau foto-foto yang } \\
\text { berhubungan dengan sector pertanian. }\end{array}$ \\
\hline Kontak & $\begin{array}{l}\text { Berisi informasi administrator pengelola aplikasi portal } \\
\text { berita E-News }\end{array}$ \\
\hline
\end{tabular}

BREAKING NEWS $\mathrm{n}$ Manado, Maladewa-nya Indonesia > Destinasi Wisata Tenta

Pusat Informasi Tentang Sektor Pertanian

beranda tentang kamiv olahantani tanaman ternak perikanan galeri kontak

\section{TENTANG KAMI}

Portal berita E-News adalah wadah untuk memberikan informasi atau berita seputar sektor pertanian, yang dimaksud dengan pertanian disini adalah kegiatan peman lingkungen hd bercocok tanam (bahasa Inggris: crop cultivation) senta pembesaran hewan ternak (ralsing), meskipun cakupannya dapat pula berupa pemanfaatan mikroorganisme dan biecnzim dalam pengolahan produk lanjutan, seperti permbuatan keju dan tempe, atau sekadar ekstraksi semata, seperti penangkapan ikan atau ekspleitasi huto.

Portal berita E-News diharapkan dapat berkontribusi untuk menyebarkan informasi yang valid dan dapat dipercaya, serta dapat turut serta memajukan sektor pertanian.

Terima kasih,

Pengelola Portal Berita E-News

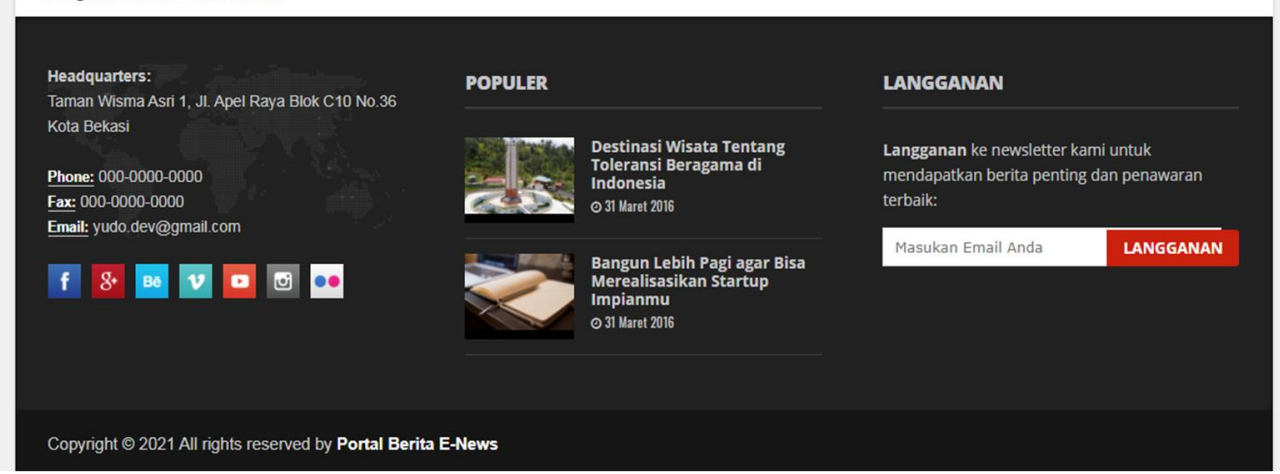

Gambar 7. Frontend Menu Tentang Kami E-News 
Data yang digunakan pada aplikasi portal berita E-News adalah bukan data sektor pertanian, data yang digunakan adalah data untuk membantu menampilkan fungsi-fungsi dari aplikasi portal berita E-News tersebut.

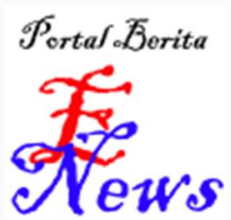

Log In Panel

\section{Username}

Forgot your password?

Gambar 8. Menu Login Backend

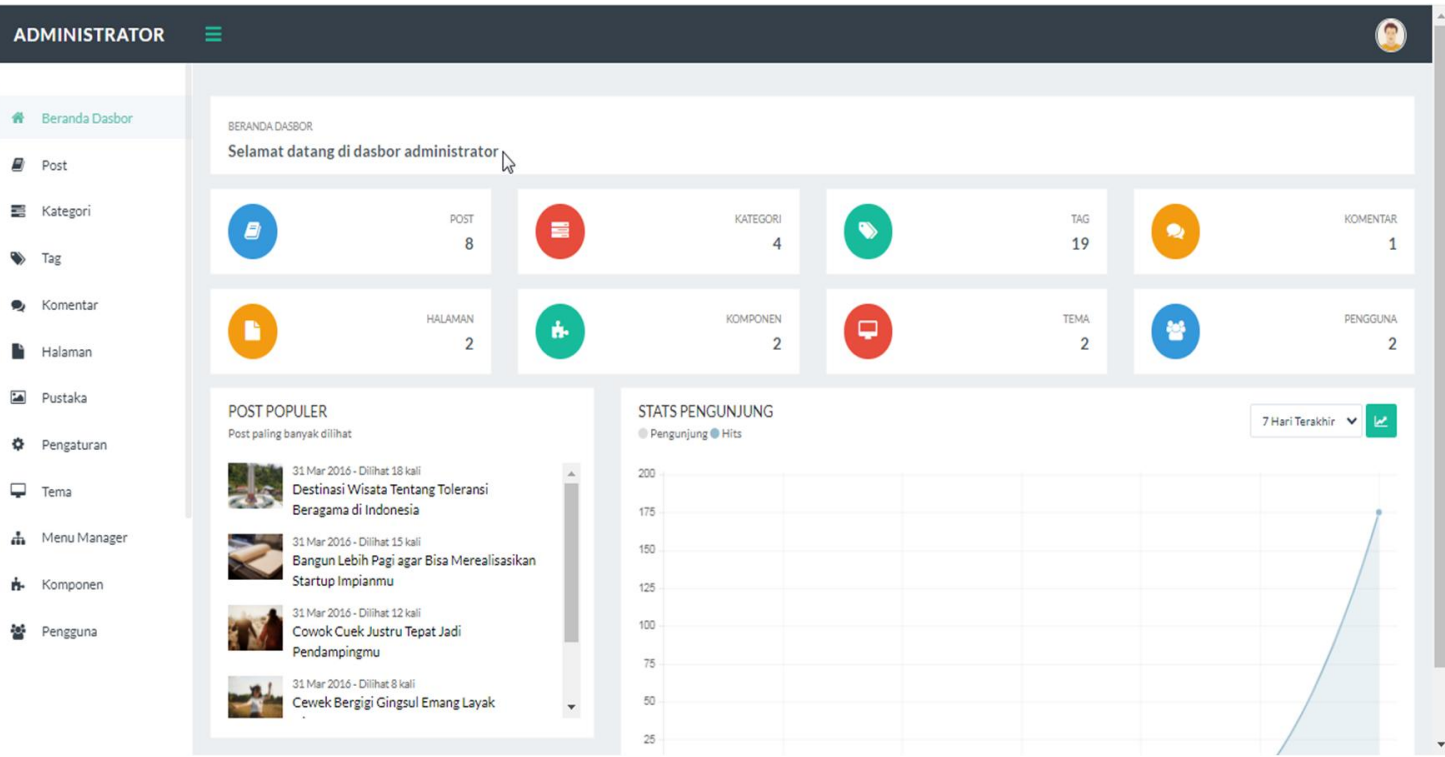

Gambar 9. Dasbor Backend Aplikasi Portal Berita E-News

Pada diagram struktur antarmuka dashboard backend aplikasi portal berita E-News, Anda dapat melihat beberapa menu yang akan digunakan untuk memasukkan data yang akan ditampilkan pada frontend. Menu yang digunakan dapat terlihat pada tabel berikut ini.

Tabel 2 Menu Backend Aplikasi Portal Berita E-News

\begin{tabular}{ll} 
Menu & Keterangan \\
\hline Post & $\begin{array}{l}\text { Pada menu ini informasi berita disimpan, dan akan } \\
\text { dimunculkan pada halaman frontend portal berita. }\end{array}$ \\
\hline Kategori & Pada menu ini berisi kategori informasi berita. \\
\hline Tag & $\begin{array}{l}\text { Penanda atau kata kunci dari informasi berita yang akan } \\
\text { ditampilkan pada halaman frontend portal berita. }\end{array}$ \\
\hline
\end{tabular}




\begin{tabular}{ll} 
Komentar & $\begin{array}{l}\text { Berisi komentar dari berita yang telah dibaca oleh } \\
\text { masyarakat. }\end{array}$ \\
\hline Halaman & $\begin{array}{l}\text { Pada menu ini informasi yang dimunculkan pada menu- } \\
\text { menu yang ada pada halaman frontend aplikasi portal } \\
\text { berita. }\end{array}$ \\
\hline Pustaka & $\begin{array}{l}\text { Berisi kumpulan gambar-gambar yang akan digunakan } \\
\text { pada aplikasi portal berita E-News. }\end{array}$ \\
\hline Pengaturan & $\begin{array}{l}\text { pada menu ini digunakan untuk mengatur konfigurasi } \\
\text { aplikasi portal berita E-News. }\end{array}$ \\
\hline Tema & $\begin{array}{l}\text { Pada menu ini digunakan untuk mengatur template } \\
\text { frontend yang akan digunakan. }\end{array}$ \\
\hline Manager & $\begin{array}{l}\text { Pada menu ini digunakan untuk mengatur posisi menu } \\
\text { yang dimunculkan pada frontend dan backend aplikasi } \\
\text { portal berita E-News. }\end{array}$ \\
\hline Komponen & $\begin{array}{l}\text { Pada menu ini mengatur menu galeri dan kontak pada } \\
\text { frontend aplikasi portal berita E-News. }\end{array}$ \\
\hline Pengguna & $\begin{array}{l}\text { Pada menu ini diatur otorisasi pengguna backend } \\
\text { aplikasi portal berita E-News. }\end{array}$ \\
\hline
\end{tabular}

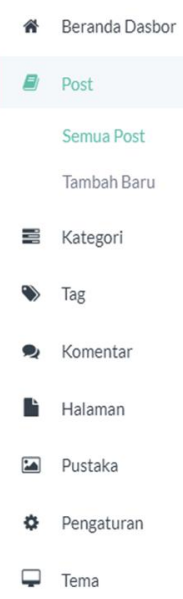

Post

Beranda basbor / Post

Show $10 \vee$ entries

Id If Kategori

ㄴ 8 Perikanan

Perikana

ㅁ Perikanan

Gambar 10. Menu Post Aplikasi Portal Berita E-News

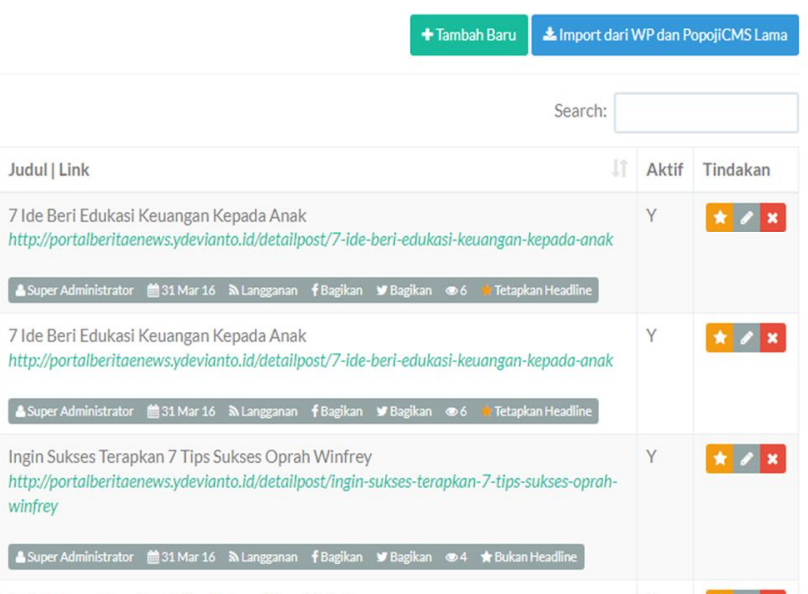

7 Ide Beri Edukasi Keuangan Kepada Anak

http://portalberitaenewsydeviantoid/detailpost/7-ide-beri-edukasi-keuangan-kepada-anak 

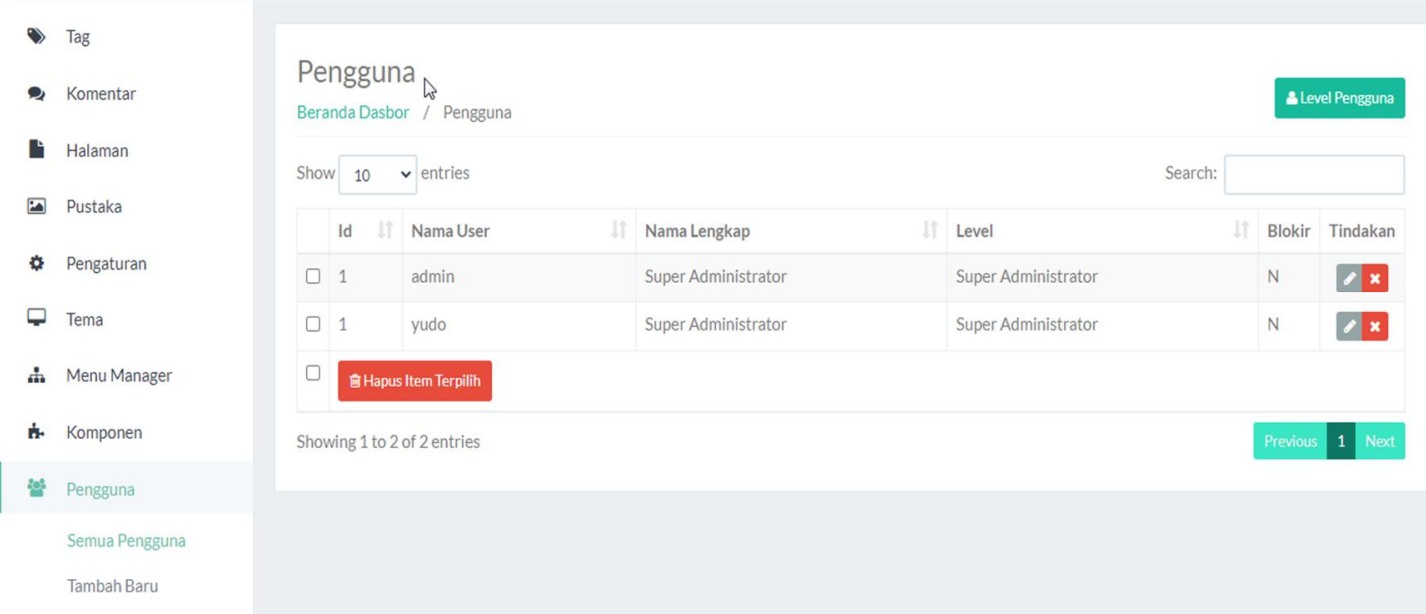

Gambar 11. Menu Pengguna Aplikasi Portal Berita E-News

Aplikasi web portal berita E-News ini dirancang untuk dapat menginformasikan berita berkaitan dengan sektor pertanian, sebagai contoh, hasil pertanian kemiri, asam dan kenari yang ada pada desa Purnama dan desa Kailesa, Nusa Tenggara Timur. Dengan adanya informasi berita dari web portal berita E-News ini, masyarakat luas dapat mengetahui perkembangan sektor pertanian, serta khususnya para petani, hasil pertanian mereka dapat dikenal oleh masyarakat luas.

\section{KESIMPULAN}

Berdasarkan hasil penelitian yang telah dibahas, maka dalam penelitian ini dapat ditarik kesimpulan. Aplikasi ini dibuat untuk membantu masyarakat mendapatkan informasi berita yang berkaitan dengan sektor pertanian. Dengan aplikasi portal berita E-News ini informasi berita yang berkaitan dengan sektor pertanian dapat tersampaikan ke masyarakat luas, khususnya masyarakat petani. Hasil dari penelitian ini adalah aplikasi portal berita E-News, yang dapat diterapkan untuk mengolah informasi berita yang berhubungan dengan sektor pertanian.

\section{SARAN}

Saran yang dapat kami sampaikan agar aplikasi ini dapat dikembangkan dan ditingkatkan lebih baik lagi dengan memanfaatkan teknologi terbarukan di bidang teknologi informasi.

\section{UCAPAN TERIMA KASIH}

Puji serta syukur kami sembahkan kepada TUHAN YME atas segala rahmat dan karunia-NYA sehingga riset internal ini berhasil diselesaikan. Tak lupa kami ucapkan terima kasih kepada keluarga kami Fakultas Ilmu Komputer Universitas Mercu Buana, dan khususnya PUSLIT Universitas Mercu Buana yang telah memberikan support dana penelitian. Tema yang 
dipilih dalam kegiatan riset internal ini "Perancangan E-News Untuk Menginformasikan Seputar Berita Tentang Pertanian“. Penulis menyadari bahwa laporan ini masih jauh dari sempurna maka dari itu kritik beserta saran yang membangun sangat penulis harapkan untuk menjadi lebih baik. Semoga laporan ini dapat memberikan manfaat bagi pembaca. Terima kasih. No SPK: 02-5/486/B-SPK/II/2021

\section{DAFTAR PUSTAKA}

[1] “Undang-undang Republik Indonesia Nomor 6 Tahun 2014 Tentang Desa," 2016.

[2] B. A. Nandari and Sukadi. 2007, "Pembuatan Website Portal Berita," Indones. J. Netw. Secur., Vol. 3, No. 3, pp. 1-14,

[3] https://aptika.kominfo.go.id/2019/08/penggunaan-internet-di-indonesia/, "Penggunaan Internet di Indonesia”, Diakses pada Tanggal 24 November 2020, 2019.

[4] https://id.wikipedia.org/wiki/Pertanian, "Pertanian", Diakses pada Tanggal 24 November 2020.

[5] A. Yani. 2017, "Pengaruh E-Business Atas Proses Dalam Organisasi Bisnis,” No. 1, pp. $16-21$.

[6] Sugiyono, 2012. "Metode Penelitian Kuantitatif, Kualitatif, dan R\&D”, Alfabeta, Bandung

[7] Team Penulis. 2020, “Rencana Induk Penelitian UMB 2021-2025”, Universitas Mercu Buana, Jakarta.

[8] A. N. Anastasia and I. Handriani, "Aplikasi Sistem Order Jasa Graphic Designer Berbasis Web pada PT. Decorner," J. Ilm. FIFO, Vol. 10, No. 1, p. 87.

[9] R. Sahara, H. Prastiawan, and D. Rizal. 2017, "Rancang Bangun Sistem Informasi Mylibrary Telkomsel Berbasis Website (Studi Kasus: PT. Telekomunikasi Selular),” J. Format, Vol. 6, No. 1, pp. 106-118.

[10] P. Tantri Fajarini, N. K. Ayu Wirdiani, and I. P. Arya Dharmaadi. 2020, "Evaluasi Portal Berita Online pada Aspek Usability Menggunakan Heurtistic Evaluation dan Think Aloud," J. Teknol. Inf. dan Ilmu Komput., Vol. 7, No. 5, p. 905.

[11] D. A. Siagian, A. Ahmad, and S. Solikhun. 2020, "Sistem Informasi Portal Berita pada Kantor Camat Tapian Dolok,” Semin. Nas. Teknol. Komput. Sains, Vol. 1, No. 1, pp. 190-196.

[12] B. A. Nandari and Sukadi. 2007, "Pembuatan Website Portal Berita Desa Jetis Lor," Indones. J. Netw. Secur., Vol. 3, Vo. 3, pp. 1-14.

[13] I. Rahmadani. 2020, "Pengembangan Portal Berita Kabupaten Bantul Berbasis Website Dengan Kosep Citizen Journalism", Doctoral Dissertation, STIMIK AKAKOM Yogyakarta. 
[14] M. Faizal and N. A. Aristarini. 2020, "Perancangan Portal Berita Daring Magazinc! Sebagai Media Informasi Mahasiswa,” J. Bhs. Rupa, Vol. 4, No. 1, pp. 28-41.

[15] M. I. Suri and A. S. Puspaningrum. 2020, "Sistem Informasi Manajemen Berita Berbasis Web,” J. Teknol. dan Sist. Inf., Vol. 1, No. 1, pp. 8-14.

[16] Y. Firmansyah, R. Maulana, and N. Fatin. 2020, "Sistem Informasi Pengaduan Warga Berbasis Website (Studi Kasus: Kelurahan Siantan Tengah, Pontianak Utara),” J. Cendikia, Vol. XIX, No. April, pp. 397-404.

[17] S. Suhartono and A. Ma'ruf. 2020, "Aplikasi Portal Berita Menggunakan Widget Recyclerview pada Android Studio,” J. Mediat., Vol. 3, No. 1, p. 10.

[18] B. Wildan, A. P. Sari, and R. Nasution. 2021, "Sistem Informasi Manejemen Surat Berbasis Web pada PT. Clipan Finance Indonesia, Tbk,” Hexagon, Vol. 2, No. 1, pp. 8590 .

[19] Wulandari and E. Aribowo. 2019, “Analisis dan Perancangan Proses Bisnis dan Basis Data Untuk SIM (Sistem Informasi Manajemen) LSP AD,” JSTIE (Jurnal Sarj. Tek. Inform., Vol. 7, No. 1, p. 52.

[20] A. N. Ulfah and M. K. Anam. 2020, “Analisis Sentimen Hate Speech pada Portal Berita Online Menggunakan Support Vector Machine (SVM), ” JATISI (Jurnal Tek. Inform. dan Sist. Informasi), Vol. 7, No. 1, pp. 1-10. 